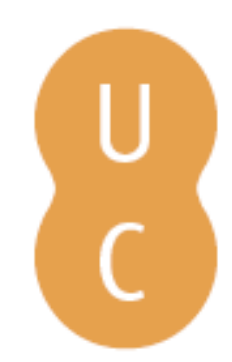

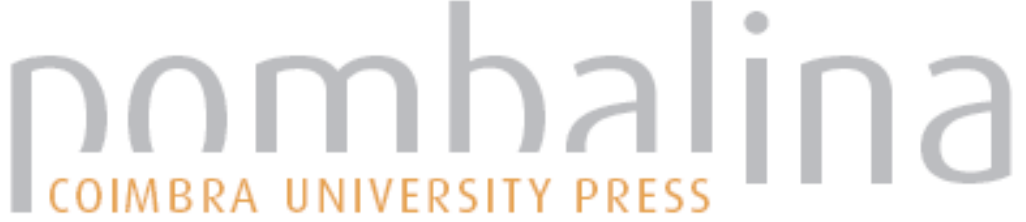

\section{Carta de equipamentos desportivos da amadora}
Autor(es):
Casanova, Sofia
Publicado por: Imprensa da Universidade de Coimbra
URL persistente:
URI:http://hdl.handle.net/10316.2/30848
DOI:
DOI:http://dx.doi.org/10.14195/978-989-26-0244-8_55

Accessed : $\quad$ 26-Apr-2023 05:30:37

A navegação consulta e descarregamento dos títulos inseridos nas Bibliotecas Digitais UC Digitalis, UC Pombalina e UC Impactum, pressupõem a aceitação plena e sem reservas dos Termos e Condições de Uso destas Bibliotecas Digitais, disponíveis em https://digitalis.uc.pt/pt-pt/termos.

Conforme exposto nos referidos Termos e Condições de Uso, o descarregamento de títulos de acesso restrito requer uma licença válida de autorização devendo o utilizador aceder ao(s) documento(s) a partir de um endereço de IP da instituição detentora da supramencionada licença.

Ao utilizador é apenas permitido o descarregamento para uso pessoal, pelo que o emprego do(s) título(s) descarregado(s) para outro fim, designadamente comercial, carece de autorização do respetivo autor ou editor da obra.

Na medida em que todas as obras da UC Digitalis se encontram protegidas pelo Código do Direito de Autor e Direitos Conexos e demais legislação aplicável, toda a cópia, parcial ou total, deste documento, nos casos em que é legalmente admitida, deverá conter ou fazer-se acompanhar por este aviso.

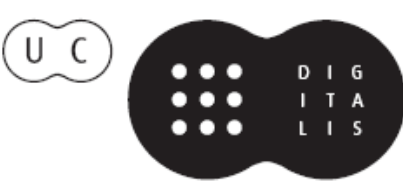




\section{TRUNFOS DE UMA}

\section{EOGRAFIA ACIVA}

\section{DESENVOLVIMENTO LOCAL,}

AMBIENTE,

ORDENAMENTO

E TECNOLOGIA

Norberto Santos

Lúcio Cunha

COORDENAÇÃO 
Sofia Casanova

Gabinete de Sistemas de Informação Geográfica, Câmara Municipal da Amadora

\section{CARTA DE EQUIPAMENTOS DESPORTIVOS DA AMADORA}

\section{Objectivos da Carta de Equipamentos Desportivos da Amadora}

Os objectivos principais da Carta de Equipamentos Desportivos (CED) assentam no eixo "Melhorar o Padrão de Vida" do Modelo de Desenvolvimento proposto pelo Plano Director Municipal (PDM) da Amadora, que propunha como objectivos de $2^{\circ}$ nível a melhoria do padrão de vida da população, a qualificação urbanística do território e a garantia de um bom nível de equipamentos, de serviços públicos de apoio à comunidade $\mathrm{e}$ infra-estruturas urbanas.

Com os objectivos específicos da CED pretende-se caracterizar a oferta, prospectivar a rede de forma integrada e optimizar o modelo de gestão dos equipamentos desportivos. Ainda em conformidade com a figura anterior, é desenvolvido um conjunto de acçóes específicas: recolher e sistematizar a informação e integrá-la em projecto SIG (Sistema de Informação Geográfica); construir o "Território Desportivo" estabelecendo uma rede integrada de instalaçôes por Território Desportivo; definir/estruturar a rede de instalaçóes desportivas com o objectivo de atingir o equilíbrio social do Concelho; prospectivar lógicas de gestão municipal integradoras - desporto, acção social, educação, juventude, cultura; planeamento prospectivo - antecipar prospectivamente a procura desportiva com base em critérios demográficos e urbanísticos e integrar a procura na programação da rede; estabelecer princípios orientadores à construção e requalificação de instalaçóes desportivas.

\section{A CED E O ORDENAMENTO DO TERRITÓRIO}

A CED está directamente relacionada com o ordenamento do território. Por um lado, porque preconiza a orientação estratégica para o desenvolvimento de políticas desportivas ao nível do espaço físico do Concelho. Por outro, porque um dos seus objectivos é o reordenamento da rede de equipamentos, através da construção do Território Desportivo. Deste modo, tendo em conta um conjunto de referências normativas, instrumentos de planeamento de âmbito municipal e documentos de diagnóstico e estratégicos sobre o Município da Amadora, é possível delinear um esquema que os situe e organize para a construção da CED, representado na figura seguinte. 
Figura 1 - Esquema Director da Carta de Equipamentos Desportivos

Coesão territorial e social

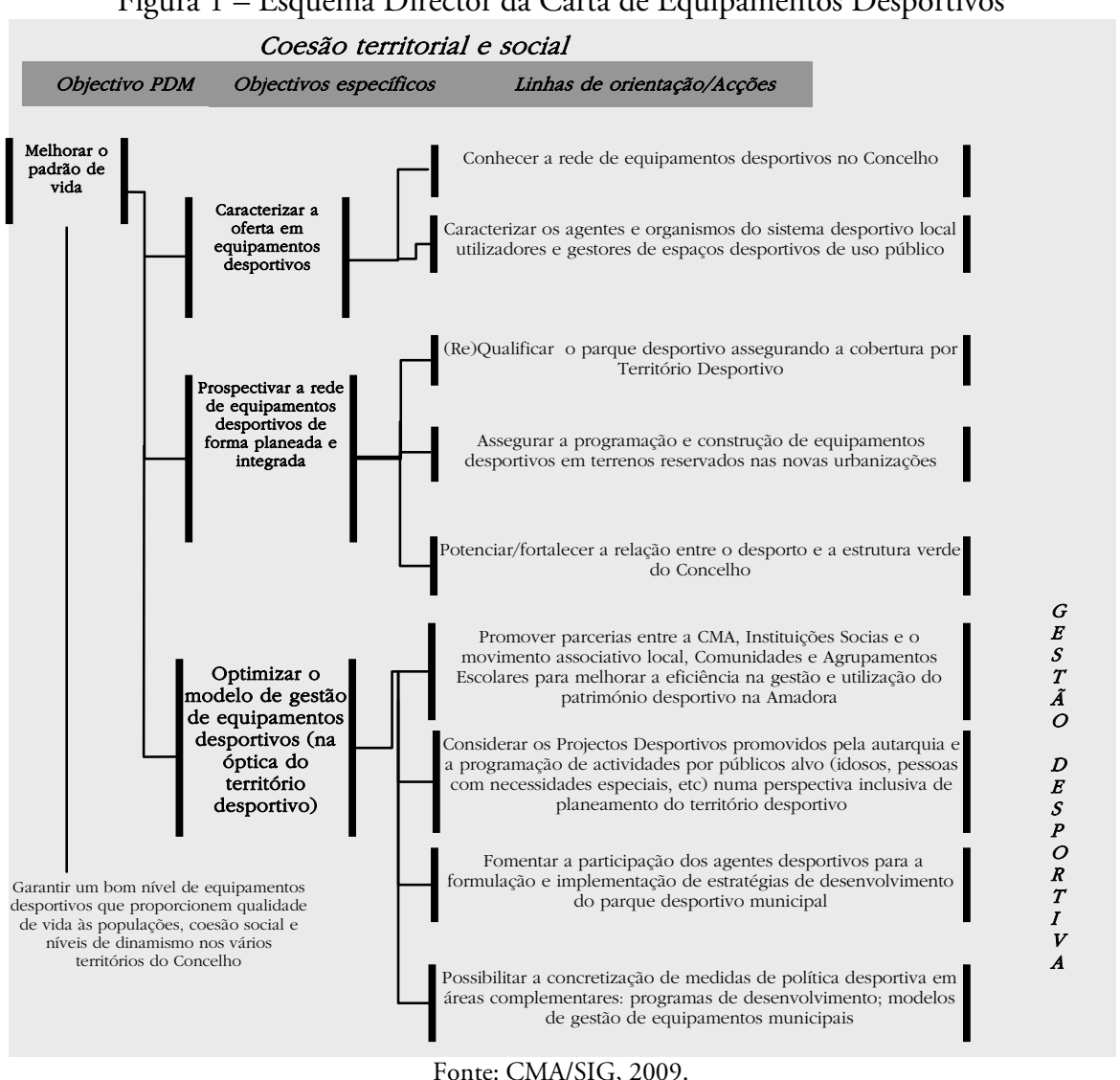

O desenvolvimento de actividades desportivas e a gestáo dos equipamentos de desporto são competências da responsabilidade das Autarquias Locais. Compete aos órgãos municipais, no âmbito do planeamento público, entre outros, a gestão e a realização de investimentos públicos em instalaçóes e equipamentos para a prática desportiva e recreativa de interesse municipal ${ }^{1}$. Compete-lhes também apoiar as actividades desportivas e recreativas tendo ainda a responsabilidade no licenciamento e fiscalização dos recintos de espectáculos. A organização do território, a correcção das assimetrias regionais e a igualdade de oportunidades dos cidadáos no acesso aos equipamentos, infra-estruturas, serviços e funçóes urbanas e o consequente reforço da coesão nacional, são o objectivo final da política de ordenamento do território e urbanismo. De facto, na Lei de Bases do Ordenamento do Território e Urbanismo ${ }^{2}$, no $\mathrm{n}^{\mathrm{o}} 2$ do artigo 6o, recomenda-se o equilíbrio das assimetrias através da programação, criação e manutenção de serviços, espaços verdes e equipamentos colectivos, nos quais se inserem os vocacionados para a actividade física e

\footnotetext{
${ }^{1}$ Segundo o art. $^{\circ}$ 64. ${ }^{\circ}$, da Lei n. ${ }^{\circ}$ 169/99, de 18 de Setembro, com as alteraçóes introduzidas pela Lei n. ${ }^{\circ}$ 5A/2002, de 11 de Janeiro, bem como o art. ${ }^{\circ} 21 .^{\circ}$ da Lei n. ${ }^{\circ}$ 159/99, de 14 de Setembro.

${ }^{2}$ Lei no 48/98, de 11 de Agosto, alterada pela Lei no 54/2007, de 31 de Agosto.
} 
para o desporto, tendo em conta as necessidades específicas das populaçóes, as acessibilidades e a adequação da capacidade de utilização.

Figura 2 - Enquadramento da Carta de Equipamentos Desportivos

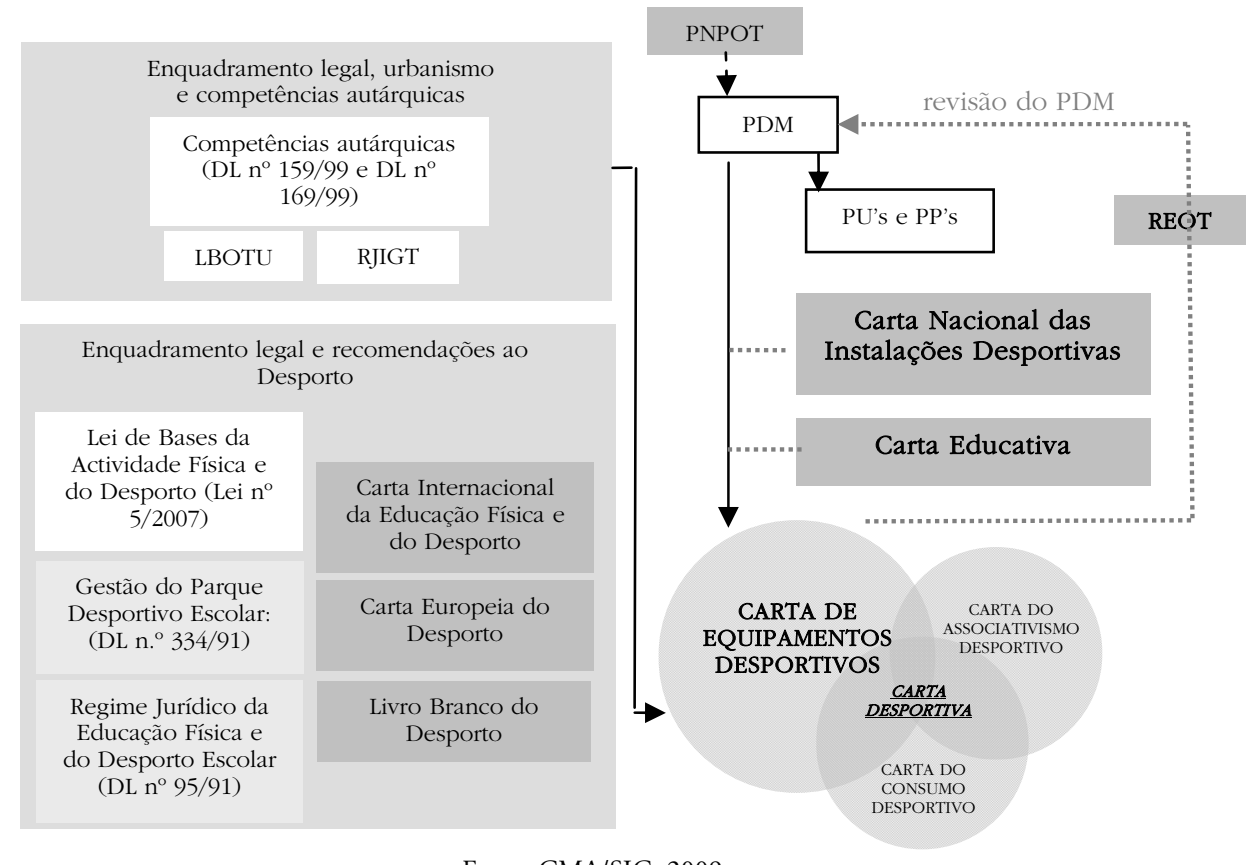

Fonte: CMA/SIG, 2009.

O Regime Jurídico dos Instrumentos de Gestão Territorial ${ }^{3}$ veio operacionalizar esta recomendação através dos instrumentos de gestáo territorial, ao estabelecer a identificação das redes de equipamentos colectivos nos planos bem como a definição de uma estratégia coerente de instalação, de conservação e de desenvolvimento das infra-estruturas ou equipamentos, tendo em conta as necessidades sociais e culturais da população e as perspectivas de evolução económico-social (n..$^{\circ} 2$ do art. $\left.{ }^{\circ} 17 .{ }^{\circ}\right)$.

Os Planos Municipais de Ordenamento do Território (PMOT) visam estabelecer os princípios e os critérios subjacentes a opçóes de localização de, entre outros, equipamentos de utilização colectiva. Por sua vez, o PDM define um modelo de organização espacial do território, o qual tem por base a classificação e a qualificação do solo. Justifica-se, assim, uma análise global que estabeleça coerência no planeamento das redes infra-estruturais e nas dinâmicas sociais subjacentes à actividade física e ao desporto, em cumprimento dos objectivos estratégicos delineados para o município. Esta matéria está presente na revisão do PDM e é objecto de monitorização e avaliação em cumprimento da obrigação de elaborar o Relatório do Estado do Ordenamento do Território (REOT), nos termos do n. 3 do artigo $146 .^{\circ}$ do Decreto-Lei n. ${ }^{\circ}$ 380/99, de 22 de Setembro.

\footnotetext{
${ }^{3}$ Decreto-Lei no 380/99, de 22 de Setembro, alterado pelo Decreto-Lei no 316/2007, de 19 de Setembro.
} 
O esquema anterior destaca também o carácter estratégico e enquadrador de outros instrumentos. Assumem esta posição o Programa Nacional da Política de Ordenamento do Território (PNPOT) e os Planos Regionais de Ordenamento do Território (PROT), os quais definem um modelo de organizaçáo espacial que estabelece, entre outras, opçóes relativamente às estruturas e redes de equipamentos. Embora estes últimos não sejam vocacionados para acçóes a nível municipal, definem orientaçóes, prioridades e medidas a ter em conta no âmbito da CED, dada a sua concepção inter-municipal.

A nova versão da Carta Nacional das Instalaçóes Desportivas constituirá um instrumento para a realizaçáo de planos e programas que regulem o acesso a financiamentos públicos e que estabeleçam estratégias e prioridades no desenvolvimento dos equipamentos e infraestruturas desportivas.

As Cartas Educativas constituem outro dos documentos estratégicos complementares à CED, ao integrar o desporto escolar. Articula-se na sua metodologia e objectivo e aplica o conceito de «Território Educativo», que se deverá cruzar com o de «Território Desportivo».

Para além deste conjunto de informação, foi ainda analisado um conjunto de referências legislativas e de documentos com recomendaçóes ao desporto.

A conclusão da CED não encerra nenhum processo. Pelo contrário, inicia um ciclo no planeamento e gestáo da política desportiva. É um dos documentos que, juntamente com a Carta do Associativismo Desportivo e com a Carta do Consumo Desportivo, permite a concretização de uma futura Carta Desportiva que deverá integrar não só o modelo de gestão dos equipamentos mas também de toda a actividade desportiva do Concelho da Amadora.

\section{A CONSTRUÇÃO DO TERRITÓRIO DESPORTIVO}

Das várias etapas metodológicas que compóem a CED destaca-se a construção do «Território Desportivo». O conceito de território reflecte o suporte, a integração e a síntese de toda a actividade humana num espaço físico circunscrito como unidade de análise e planeamento. Nesse sentido é necessário aprofundar as complementaridades entre diferentes tipologias de equipamentos, promover a centralidade da sua localização, na relação entre a sua distribuição e a ocupaçáo populacional do território e, em última análise, propiciar a mobilização da população para a prática desportiva. O TD poderá constituir, sob o ponto de vista da gestáo, um elemento estruturador na dinamização de interdependências sinérgicas com outros intervenientes relevantes no desporto local, nomeadamente, o movimento associativo, as juntas de freguesia, a comunidade escolar e o tecido empresarial.

Com o Território Desportivo pretende-se perspectivar a rede de equipamentos desportivos de forma planeada e integrada, com vista a: garantir um bom nível e uma oferta diversificada de equipamentos desportivos em cada território que proporcionem qualidade de vida às populaçóes, corrijam assimetrias e promovam a coesão social e níveis de dinamismo nos vários territórios do Concelho; promover a articulação entre actores do tecido desportivo local, de modo a construir parcerias relevantes para a criaçáo de valor desportivo no Concelho da Amadora; desenvolver uma acção concertada com os agrupamentos escolares e agentes de outras redes sociais de modo a maximizar a funcionalidade e a utilização das respectivas instalaçóes desportivas; assegurar a programação e construção de equipamentos desportivos, eficientes e funcionais, em terrenos reservados nas novas urbanizaçóes; possibilitar a delineação de medidas de política desportiva no que diz respeito a programas de desenvolvimento e a modelos de gestão de equipamentos municipais. 


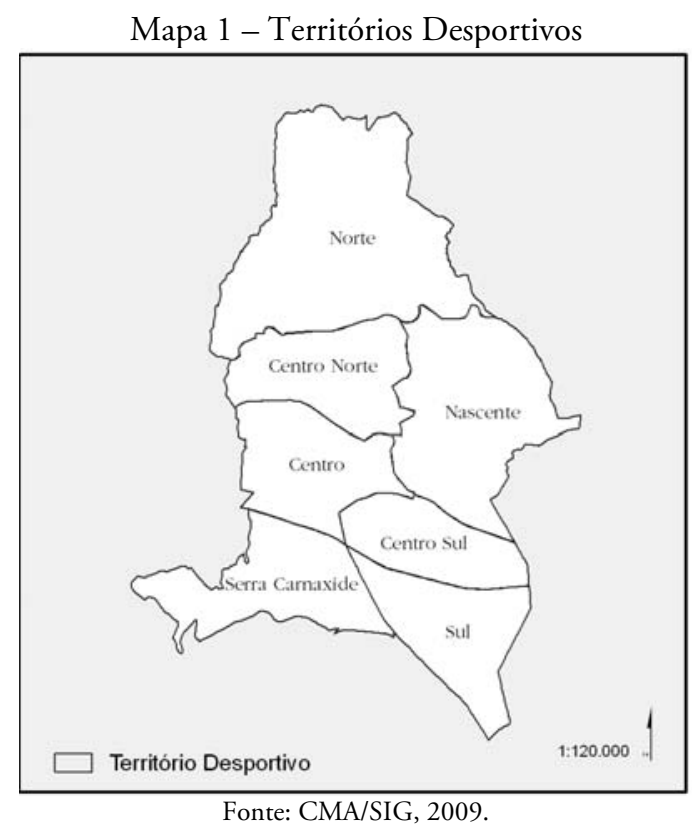

O cruzamento destes critérios num território heterogéneo como é o da Amadora conduz à procura da melhor solução para cada sub-secção territorial. Importa, no entanto, conhecer e analisar cada Território Desportivo no que diz respeito à cobertura em equipamentos desportivos.

\section{METODOLOGIA PARA A ANÁLISE DO TERRITÓRIO NA COBERTURA EM EQUIPAMENTOS DESPORTIVOS}

No actual contexto de diversificação de tipos de prática desportiva, que vão desde a simples actividade lúdica e recreativa, até ao desporto rendimento e de alta competição, passando pela formaçáo desportiva competitiva, impóe-se também a necessidade de diferenciar tipologicamente os equipamentos em função dos requisitos que oferecem para concretizar estes diferentes níveis de prática. Esta hierarquização é complementada com a componente geográfica de modo a estabelecer equilibradamente a distribuiçáo das instalaçôes desportivas numa lógica de rede, visando dar uma resposta que viabilize a generalização da prática desportiva à população.

Neste sentido analisam-se as diversas necessidades populacionais em matéria de espaços desportivos, sejam elas de competição, de actividade escolar, de actividade física em espaço público de recreio, ou usufruto das dimensóes desportivas oferecidas em áreas verdes e parques urbanos. É este jogo de diversidade na oferta e sua distribuição geográfica que compóe e estrutura uma rede integrada de equipamentos desportivos. As novas exigências, ou a reconfiguração das necessidades em função de estilos de vida activos que alimentam a procura desportiva, tornam premente a concepção da actividade física, recreativa e desportiva socialmente integrada. Deste modo pretende-se, em primeira instância, dar resposta à procura por parte de públicos diferenciados e, assim, criar hábitos que valorizem e sustentem essa procura. 
Quadro 1 - Variáveis e indicadores da Carta de Equipamentos Desportivos

\begin{tabular}{|c|c|c|c|c|}
\hline \multirow{3}{*}{$\begin{array}{l}\text { Tipo Inst. } \\
\text { Desp } \\
\text { Origem } \\
\text { Indicador }\end{array}$} & \multicolumn{4}{|c|}{ Espaços construídos ou espaços artificiais } \\
\hline & \multirow{2}{*}{ Total } & \multicolumn{2}{|c|}{ Instalaçôes desportivas de base } & \multirow{2}{*}{\begin{tabular}{|c|}
$\begin{array}{c}\text { Parque } \\
\text { desportivo } \\
\text { escolar (público) }\end{array}$ \\
formativa \\
\end{tabular}} \\
\hline & & formativa & recreativa & \\
\hline \multirow{5}{*}{ 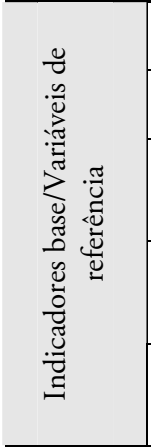 } & Pop/TD (no hab) & Pop/TD (no hab) & $\begin{array}{l}\text { No hab } 0-13 \text { anos } / n^{\circ} \\
\text { inst. de recreio }\left(n^{\circ} \text { hab) }\right.\end{array}$ & $\begin{array}{l}\text { Pop. escolar ( } \mathrm{n}^{\circ} \\
\text { alunos) }\end{array}$ \\
\hline & Área útil/hab $\left(\mathrm{m}^{2}\right)$ & Área útil/hab $\left(\mathrm{m}^{2}\right)$ & $\begin{array}{l}\text { Área útil/hab 0-13 anos } \\
\left(\mathrm{m}^{2}\right)\end{array}$ & $\begin{array}{l}\text { No inst. desp. } \\
\text { escolares ( } n^{\circ} \text { un.) }\end{array}$ \\
\hline & $\begin{array}{l}\text { No hab/no inst ( } \mathrm{n}^{\circ} \\
\text { hab) }\end{array}$ & No hab/no inst ( $n^{\circ}$ hab) & Dimensão média $\left(\mathrm{m}^{2}\right)$ & $\begin{array}{l}\text { No inst. desp. } \\
\text { escolares } \\
\text { cobertas ( } n^{\circ} \text { un.) }\end{array}$ \\
\hline & $\begin{array}{l}\text { Dimensão média } \\
\text { das instalaçôes }\left(\mathrm{m}^{2}\right)\end{array}$ & $\begin{array}{l}\text { Dimensão média das } \\
\text { instalaçóes }\left(\mathrm{m}^{2}\right)\end{array}$ & & $\begin{array}{l}\text { Área inst. } \\
\text { desp. escolares } \\
\text { cobertas }\left(\mathrm{m}^{2}\right)\end{array}$ \\
\hline & & & & $\begin{array}{l}\text { Pop. escolar } / \mathrm{n}^{\circ} \\
\text { inst. desp. cobertas } \\
\text { ( } \mathrm{n}^{\circ} \text { alunos) }\end{array}$ \\
\hline \multirow{2}{*}{$\begin{array}{l}5 \\
\mathfrak{0} \\
0 \\
0\end{array}$} & & $\begin{array}{l}\text { Área influência DGOTDU: } \\
\text { por tipologia (cartografado) }\end{array}$ & $\begin{array}{l}\text { Área influência } \\
\text { (adaptado): } 400 \mathrm{~m} \\
\text { (cartografado) }\end{array}$ & \\
\hline & & $\begin{array}{l}\text { Dotaçáo funcional por Tipo } \\
\text { de Inst. e por TD: área } \\
\text { útil/hab. }\left(\mathrm{m}^{2}\right)\end{array}$ & & \\
\hline \multirow[t]{2}{*}{ ๑ี } & & $\begin{array}{l}\text { Pop. por área de influência } \\
\text { inst. desp.: } n^{\circ} \text { hab residentes } \\
\text { dentro e fora da área de } \\
\text { influência( } n^{\circ} \text { hab) }\end{array}$ & $\begin{array}{l}\text { Pop. por área de influên- } \\
\text { cia inst. desp.: } \mathrm{n}^{\circ} \text { hab re- } \\
\text { sidentes dentro e fora da } \\
\text { área de influência ( } \mathrm{n}^{\circ} \text { hab) }\end{array}$ & \\
\hline & & $\begin{array}{l}\text { Área de influência inst. desp. } \\
\text { (adaptado): } 500 \text { metros }\end{array}$ & & \\
\hline \multirow{3}{*}{$\overbrace{0}^{\infty}$} & & Área útil/23\% pop. $\left(\mathrm{m}^{2}\right)$ & & \\
\hline & & $\begin{array}{l}23 \% \text { pop. } / \mathrm{n}^{\circ} \text { inst. desp. ( } \mathrm{n}^{\circ} \\
\text { hab) }\end{array}$ & & \\
\hline & & $\begin{array}{l}\text { Dotaçáo funcional por Tipo } \\
\text { de Inst. e por TD: área } \\
\text { útil/23\% pop. }\left(\mathrm{m}^{2}\right)\end{array}$ & & \\
\hline 菿茫 & & & & $\begin{array}{l}\text { Área inst. } \\
\text { desp. coberta/aluno } \\
\left(\mathrm{m}^{2} / \text { aluno }\right)\end{array}$ \\
\hline
\end{tabular}

Fonte: CMA/SIG, 2009.

NOTAS: 1 - Normas de Programação de Equipamentos Colectivos - DGOTDU

2 - Carta de Equipamentos Desportivos da Amadora - análise conjunta da área de influência com as subsecçóes estatísticas da Base Geográfica de Referenciação de Informação do INE

3 - Critério aplicado na análise das instalaçóes desportivas que consiste no apuramento de uma procura desportiva de acordo com a referência nacional: 23 em cada 100 pessoas praticam desporto, ou realizam semanalmente uma actividade física, pelo menos durante uma hora. Este critério está na origem de um estudo elaborado pelo Centro de Estudos e Formação Desportiva por Marivoet, 2001.

4 - Critérios de Reordenamento da Rede Educativa - Departamento de Avaliaçáo, Prospectiva e Planeamento, Ministério da Educação.

A construção de grelhas de análise para os equipamentos desportivos serve o propósito de definir um quadro de referência com base nas normas em vigor (Normas de Programação de Equipamentos Colectivos da Direcçáo Geral de Ordenamento do Território e Desenvolvi- 
mento Urbano - DGOTDU), na medida em que fornecem uma visão parametrizada das carências e da realidade do território em estudo, por tipologia de instalaçóes. No entanto, a sua aplicação carece da construção de outros indicadores e da utilização de outras variáveis com o objectivo de atingir critérios de programação funcionais e adequados à situação desportiva do município e à singularidade do seu parque desportivo.

Foram utilizados as seguintes variáveis e indicadores para a análise à cobertura do parque desportivo na Amadora:

As instalaçóes desportivas, do ponto de vista urbano, são objectos que ocupam e consomem espaço que vai para lá da delimitação física do edificado e espaços adjacentes. A sua funcionalidade define o próprio espaço das cidades, cidades essas que geram fluxos de pessoas, criam atractividade e áreas de influência, organizando o território. «Destinam-se por um lado à satisfação das necessidades desportivas das populaçóes, mas são, ao mesmo tempo, objectos pelos quais essa mesma comunidade se revê e se afirma pela própria identificação" (Cunha, 2007).

A procura de espaços desportivos inclui também os espaços públicos urbanos, as praças, jardins, equipamentos sociais e culturais, centros comerciais, etc. A produção de espaço desportivo e de recreio constitui hoje uma necessidade e uma resposta artificial ao encerramento quer dos acessos ao espaço natural quer ao condicionamento da livre utilização dos espaços públicos urbanos. Na Amadora, para além dos equipamentos desportivos de dimensão e atractividade relevante, há também alguns parques urbanos de recreio e lazer que proporcionam uma forte componente desportiva com mais ou menos informalidade. Nos últimos anos a aposta do Município em parques desta natureza, que em algumas situaçóes coincidiu com áreas muito desqualificadas em termos urbanísticos, estimulou a presença de verde associada a diferentes temáticas, a maior parte delas associadas, por sua vez, ao motricionismo e, de certa forma, à prática desportiva.

\section{AVALIAÇÃO DE NECESSIDADE, PROPOSTAS E PRIORIDADES}

Este conjunto de informação, depois de trabalhada e estudada, deu origem aos três quadros seguintes, onde está sintetizada a análise que permitiu a delineação de estratégias e respectivas propostas para cada Território Desportivo. No primeiro quadro apontam-se as necessidades mais imediatas ao nível de instalaçóes de base formativa. No segundo e terceiro quadros fez-se uma avaliação global que resulta da média ponderada do nível de necessidades que cada TD obtém em relação a cada indicador. Esta avaliação foi elaborada de forma qualitativa e quantitativa a partir da análise à cobertura em instalaçóes e equipamentos desportivos no Concelho. Uma vez que as Normas de Programaçáo de Equipamentos da DGOTDU (critérios de programação de equipamentos e de avaliação de necessidades) nem sempre se adequam à realidade desportiva actual, pois tratam-se de referências de orientação muito focalizadas para tipologias formais, são apontadas algumas consideraçóes críticas relativas à leitura de cada quadro e das respectivas propostas.

$\mathrm{O}$ quadro seguinte baseia-se na cobertura em equipamentos desportivos de acordo com a dotação funcional segundo o critério de procura por parte de $23 \%$ da população. A tipologia assinalada como prioridade em cada TD apresenta um rácio de $\mathrm{m}^{2}$ por habitante inferior ao índice do Concelho, ou seja, é deficitária comparativamente à média do Município. Relativamente às salas de desporto não foram identificadas prioridades de intervenção uma 
vez que todos os TD detêm uma área desportiva por habitante superior à desejável $\left(0,15 \mathrm{~m}^{2} / \mathrm{hab}^{4}\right)$, embora alguns Territórios apresentem um rácio inferior à média concelhia.

Quadro 2 - Avaliação de Necessidades em Instalaçóes de Base Formativa, por TD

\begin{tabular}{l|c|c|c|c|c|}
\hline \multicolumn{1}{c}{ TD } & $\begin{array}{c}\text { Grande } \\
\text { campo } \\
\text { jogos }\end{array}$ & $\begin{array}{c}\text { Pequeno } \\
\text { campo } \\
\text { jogos }\end{array}$ & Piscina & $\begin{array}{c}\text { Sala } \\
\text { Desporto }\end{array}$ & $\begin{array}{c}\text { Pista } \\
\text { Atletismo }\end{array}$ \\
\hline Sul & & & & & \\
\hline Centro & & & & & \\
Norte & & & & & \\
\hline Centro & & & & & \\
\hline Centro Sul & & & & & \\
\hline Nascente & & & & & \\
\hline Norte & & & & \\
\hline
\end{tabular}

Prioridade

Relativamente às instalaçôes desportivas de base formativa inseridas no Parque Escolar e à avaliação global da cobertura em instalaçóes de base formativa acessíveis à população de acordo com determinados parâmetros as prioridades são, respectivamente:

O campo «avaliação global» dos dois últimos quadros refere-se à média dos respectivos campos anteriores e estabelece a hierarquia das prioridades/necessidades. No entanto, como já referido, a leitura crítica aos quadros corrige eventuais distorçóes que o desfasamento entre o levantamento de campo dos equipamentos desportivos e a formulação de propostas possa ter dado origem. Por exemplo, para alguns Territórios Desportivos mais deficitários foi aprovada, no decorrer da elaboração deste documento, a construção de instalaçóes de base formativa cobertas em algumas escolas do Concelho pelo que foi necessário ponderar a leitura do quadro 2 .

Quadro 3 - Avaliação Global de Prioridades em Instalaçóes de Base Formativa Cobertas e Não Cobertas no Parque Escolar, por TD

\begin{tabular}{lcccc}
\hline TD & $\begin{array}{c}\text { No } \\
\text { alunos/inst. } \\
\text { total }\end{array}$ & $\begin{array}{c}\text { Alunos/ } \\
\text { Inst. coberta }\end{array}$ & $\begin{array}{c}\text { Área inst. cobertas/ } \\
\text { aluno }\end{array}$ & $\begin{array}{c}\text { Avaliaçáo } \\
\text { global }\end{array}$ \\
\hline Sul & 5 & 4 & 1 & 3 \\
\hline Centro & 1 & 2 & 3 & 1 \\
Norte & 6 & 3 & 5 & 6 \\
\hline Centro & 4 & 5 & 2 & 4 \\
\hline Centro Sul & 2 & 1 & 6 & 2 \\
\hline Nascente & 3 & 6 & 4 & 5 \\
\hline Norte & NOTA: 1 - prioridade maior; 6- prioridade menor &
\end{tabular}

\footnotetext{
${ }^{4}$ Critério das Normas de Programação de Equipamentos, da DGOTDU.
} 
Quadro 4 - Avaliação Global da Cobertura em Instalaçôes de Base Formativa Acessíveis à População, por TD

\begin{tabular}{lccccc}
\multicolumn{1}{c}{ TD } & $\begin{array}{c}\text { Área } \\
\text { útil/hab }\end{array}$ & $\begin{array}{c}\text { No } \\
\text { hab/inst } \\
\text { desp }\end{array}$ & $\begin{array}{c}\text { Dimensáo } \\
\text { média inst } \\
\text { desp }\end{array}$ & $\begin{array}{c}\text { Área } \\
\text { influência } \\
\text { (DGOTDU) }\end{array}$ & $\begin{array}{c}\text { Avaliaçáo } \\
\text { global }\end{array}$ \\
\hline Sul & 5 & 6 & 2 & 6 & 5 \\
\hline $\begin{array}{l}\text { Centro } \\
\text { Norte }\end{array}$ & 2 & 4 & 3 & 6 & 3 \\
\hline Centro & 6 & 5 & 4 & 6 & 6 \\
\hline Centro Sul & 4 & 3 & 5 & 6 & 4 \\
\hline Nascente & 1 & 2 & 1 & 6 & 1 \\
\hline Norte & 3 & 1 & 6 & 1 & 2 \\
\hline \multicolumn{7}{r}{ NOTA: $1-$ prioridade maior; 6-prioridade menor }
\end{tabular}

Em função da análise de toda a CED e do consequente apuramento e avaliação das carências e prioridades concelhias em termos de equipamentos desportivos, propóe-se então um conjunto de espaços vocacionados para a prática desportiva, formal ou informal, que deverá satisfazer a procura por parte da comunidade, da população escolar e do Movimento Associativo.

$\mathrm{Na}$ formulaçáo das propostas destacam-se quatro vectores fundamentais que se pretende implementar no sistema de desenvolvimento da rede de equipamentos desportivos na Amadora: criação de núcleos desportivos de base recreativa infantis e juvenis que proporcionem a prática desportiva, informal e não codificada; criação e requalificação de instalações desportivas de base formativa, promovendo a sua integração em espaço de recreio e lazer; integração de valências desportivas nos grandes espaços verdes de lazer e recreio previstos para o Concelho; valorização da oferta desportiva em piscinas, respondendo à elevada procura destes equipamentos, para fins lúdicos, desportivos e terapêuticos.

A CED deve ser entendida como um processo, sujeita a monitorização e consequentes actualizaçóes, no todo ou em parte, de modo a ajustar as propostas formuladas à realidade de cada momento, no que respeita à demografia, ao território e, sempre que possível, às tendências de procura e desenvolvimento do desporto na Amadora.

\section{CONSIDERAÇÓES FINAIS}

As transformaçóes socioculturais observadas nos últimos anos têm vindo a introduzir alteraçóes importantes nos parâmetros convencionais de actividade física e prática desportiva, motivando a urgência de orientaçóes que suportem as decisóes políticas num contexto sócio-desportivo que se reconfigura. No aspecto específico da programação de áreas desportivas é evidente a necessidade da adopção de estratégias urbanísticas centradas na criação de espaços mais flexíveis e polivalentes destinados à prática informal das actividades desportivas. A disponibilidade de equipamentos de carácter formativo que permitam a prática desportiva e a ocupação de tempos livres da populaçáo em geral constitui também um vector fundamental para a sua qualidade de vida. Portanto as decisóes sobre a infra-estruturação desportiva do território jogam-se entre estas duas grandes dimensóes que compóem o serviço público desportivo. 
A operacionalização e consolidação do modelo estratégico da CED compromete-se com novos mecanismos de trabalho, numa lógica incremental de criação de valor desportivo para o Concelho, com o objectivo de dotar a Amadora de um parque desportivo funcional e adequado às necessidades dos munícipes e dos agentes locais, com um regime de utilização efectivo, socialmente eficiente, economicamente sustentável e desportivamente satisfatório.

\section{REFERÊNCIAS BIBLIOGRÁFICAS}

Cunha, L. M. 2007, Os Espaços do Desporto. Uma gestão para o desenvolvimento humano, Almedina, Coimbra.

Departamento de Avaliação Prospectiva e Planeamento, Ministério da Educação, 2000, Critérios de Reordenamento da Rede Educativa, ME, Lisboa.

Direcção Geral de Ordenamento do Território e Desenvolvimento Urbano, 2002, Normas Programação de Equipamentos Colectivos, DGOTDU, Lisboa.

Marivoet, S. 2001, Hábitos Desportivos da População Portuguesa, Centro de Estudos e Formação Desportiva, Lisboa. 